\title{
Reflexões Éticas em Pesquisas com Populações Indígenas
}

Reflections about ethics on research related to native populations
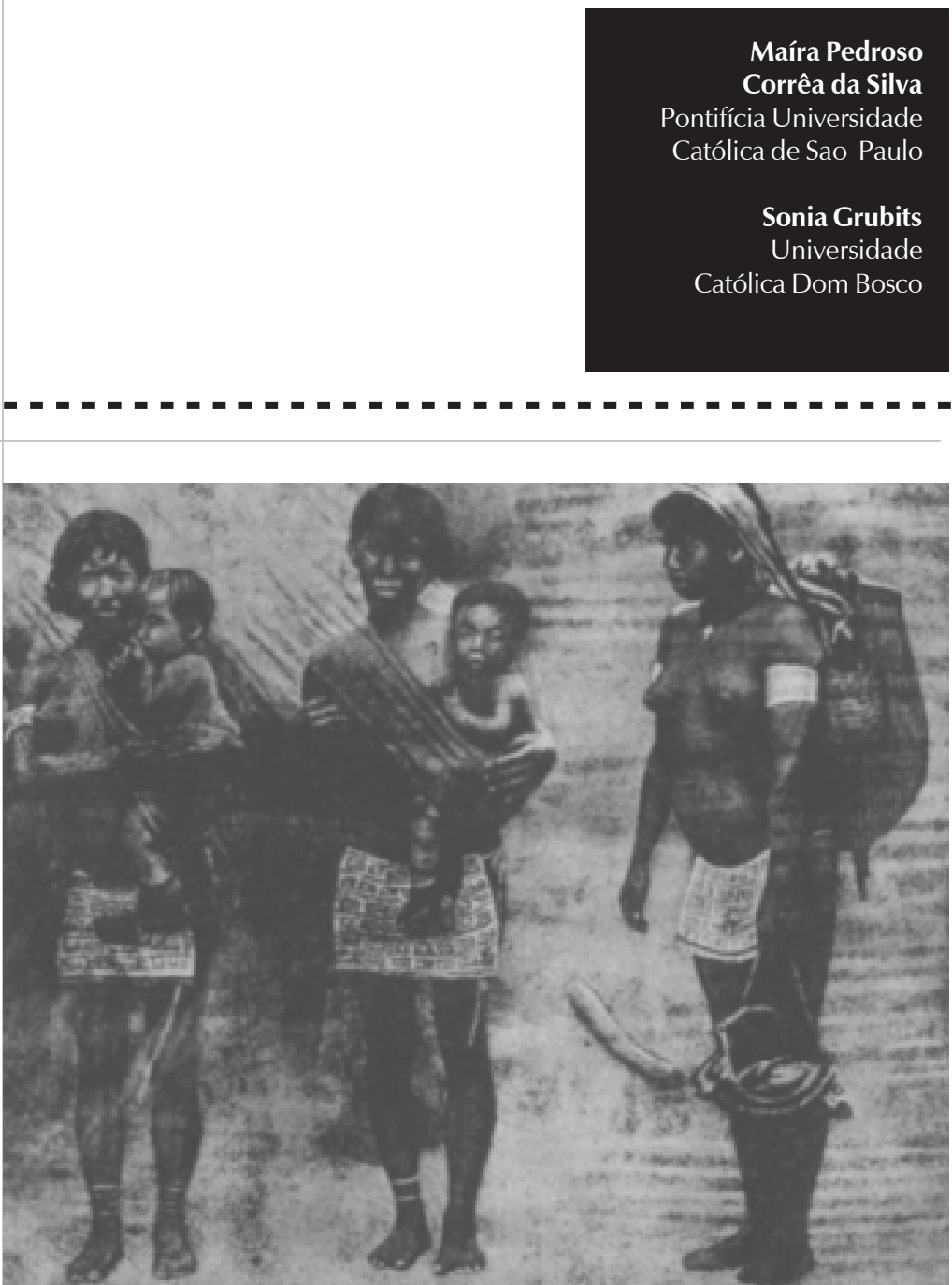


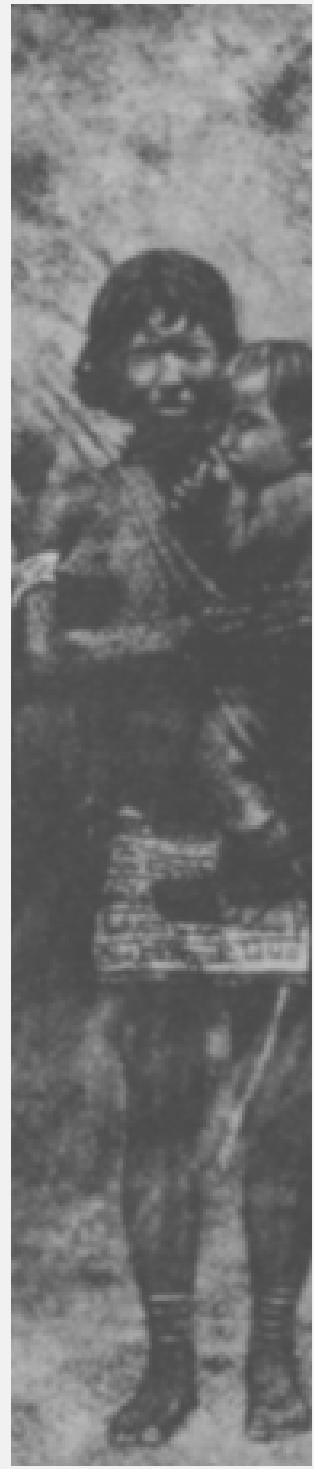

Resumo: O presente trabalho apresenta um conjunto de reflexões acerca das questões éticas que envolvem a pesquisa com povos indígenas no âmbito da Psicologia social. Partindo da questão "para que e para quem determinado saber é produzido?" iniciamos nossa reflexão, inserindo-a numa discussão ética e política que acreditamos ser fundamental para toda pesquisa. Partilhando das discussões de Guareschi (2003), baseamonos numa concepção de ética enquanto instância crítica, o que significa considerá-la uma busca incessante por transformação, o que também quer dizer que ela precisa ser propositiva e, por fim, que a ética só pode se referir às relações, sendo, ela mesma, sempre uma relação. A partir desses três pontos, realizamos uma reflexão acerca das pesquisas com grupos indígenas, acreditando que posicionar-se dentro de determinados valores é fundamental para que não se continue repetindo os abusos que têm sido cometidos ao longo da História em relação a essa população.

Palavras-chave: ética, populações indígenas, Psicologia social.

Abstract: This work presents a set of reflections about ethical questions involving research with native people within the Social Psychology area. To start our reflection we begin with the question "what for and for whom a specific knowledge is produced?", inserting it in an ethical and political discussion that we believe to be fundamental for the whole research. Sharing the discussions of Guareschi (2003), we have based our work on a conception of ethics as an instance of criticism, what means considering it as an incessant search for transformation, and a propositive subject as well, and, finally, it means that ethics can only refer to relationships, since it is actually a relationship itself. Starting from these three statements we have proceeded a reflection about the research with native groups, believing that focusing within certain values is fundamental to avoid the repetition of the same abusive behavior toward these populations during History.

Key words: ethics, native populations, Social Psychology.

Há inúmeras perguntas que, logo de início, se fazem presentes quando a questão "pesquisa com grupos indígenas" é suscitada: a pesquisa não pode interferir negativamente na cultura indígena? Não acaba sendo pior? Por que não deixar os índios em paz? Uma pesquisa pode contribuir? Pode atrapalhar? Quando e por que essas coisas podem acontecer? Como inserir-se na comunidade indígena onde será realizada a pesquisa? Como se dá o encontro entre culturas? Entre o índio e o não índio? Como se dá essa relação com toda a carga histórica de dominação e destruição que sempre esteve atrelada ao encontro do índio com o homem ocidental? Essas são perguntas essenciais para pesquisadores que pretendem trabalhar com grupos indígenas, e o presente artigo constitui um apanhado de reflexões suscitadas a partir dessas indagações, advindas da prática de 
"O campo-tema é, portanto, o argumento no qual estamos inseridos, argumento esse que tem múltiplas faces e

materialidades, que acontecem em muitos lugares diferentes"

Spink pesquisa das respectivas autoras junto a grupos indígenas de Mato Grosso (bororo e tapirapé) e Mato Grosso do Sul (guarani/kaiowá, terena e kadiwéu), no âmbito da Psicologia social. Baseando-se na discussão do Núcleo de Organização e Ação Social (NOAS) do Programa de Pós-graduação em Psicologia Social da Puc-SP, coordenado por Peter Spink (2003), partimos da consideração que entramos no campo a partir do momento em que escolhemos o tema. Dessa forma, afastando-se do modelo proposto pela Antropologia tradicional - que, ao falar da pesquisa de campo, está referindo-se à observação e interação com as pessoas "no seu habitat natural" - partimos da idéia de que o campo não é um lugar específico, mas a situação de um assunto, estando presente em múltiplos e variados lugares. Para a Psicologia social, portanto, o campo começa quando nos vinculamos a uma determinada temática, quando elegemos um assunto como psicologicamente relevante, algo que não consiste em um processo simples e sem problemas, gerando questões éticas importantes, como discutiremos adiante.

Dessa maneira, campo, aqui, não é um lugar específico, delineado, separado e distante; ele é a situação de um determinado tema, é um campo-tema. O campo-tema é, portanto, o argumento no qual estamos inseridos, argumento esse que tem múltiplas faces e materialidades, que acontecem em muitos lugares diferentes (Spink, 2003). Assim, quando escolhemos trabalhar com a questão indígena, já estamos no campo da questão indígena muito antes de entrarmos especificamente no local da reserva ou da aldeia, estando o assunto presente em múltiplas territorialidades.

A partir disso, todas as perguntas levantadas inicialmente podem ser integradas em uma questão primeira, que pode ser considerada o ponto inicial da pesquisa e que irá norteá-la durante todo o seu processo, continuando, inclusive, para além dela. Uma questão aqui partilhada com a posição construcionista: para quem e para que determinado saber é produzido? Essa questão deve ser inserida numa discussão ética e política, sendo fundamental para o desenvolvimento de toda e qualquer pesquisa, estendendo-se inclusive a outros campos do saber científico, assim como a outras áreas de investigação da Psicologia.

Na pesquisa com grupos indígenas, a discussão ética é essencial. De fato, ao longo da História, e ainda nos dias de hoje, nota-se um abuso nas pesquisas com etnias indígenas. Há inúmeros casos de pesquisadores que coletaram seus dados e nunca mais voltaram às reservas para apresentar e discutir os resultados das investigações; publicaram trabalhos sem que os próprios grupos soubessem ou autorizassem; apropriaram-se de conhecimentos da cultura e desapropriaram seus próprios donos desse conhecimento; enfim, há uma série de formas abusivas que permearam e permeiam ainda hoje as pesquisas com grupos indígenas e que tornam esse um campo bastante delicado e complexo. Além disso, a própria história do contato entre as diferentes culturas, entre índios e não índios, é uma história carregada de violência, desrespeito e dominação.

Assim, as indagações começam desde que o tema é definido. Ao entrar em campo (no campo-tema) nos deparamos com dois discursos principais:

um que aponta o fato de que as sociedades indígenas não estão em paz, portanto, a questão de deixá-las ou não em paz não é a questão fundamental. A questão fundamental é o fato de que esses grupos precisam de parceiros na luta pela conquista e reconquista de seu espaço (geográfico, cultural, político). Esse discurso revela que o avanço da sociedade nacional dominante é algo em crescente movimento e difícil de ser freado. Portanto, 
cada vez mais, os grupos indígenas precisam de pessoas envolvidas que estejam dispostas a lutar com eles e apoiá-los em sua busca por um reconhecimento e poder de negociação como grupos coesos e efetivamente inseridos na política nacional.

- por outro lado, há um discurso pautado na questão de que as pesquisas com grupos indígenas muito pouco têm contribuído para essa luta e para um auxílio efetivo nas questões pertinentes para esses grupos, o fato de que os pesquisadores têm pouco ou nenhum envolvimento político com a questão indígena e de que suas pesquisas servem apenas para si mesmos e não para os grupos aos quais se referem.

Esse segundo discurso aponta a forma abusiva que tem marcado as pesquisas com grupos indígenas, pesquisas que não são necessariamente "não éticas", mas que se pautam numa compreensão de ética muitas vezes diferente da pressuposta em nossas pesquisas.

Esse discurso sobre a questão abusiva das pesquisas com grupos indígenas é tão marcante e reflete uma história de relação entre grupos indígenas e pesquisadores tão desigual que muitas etnias passaram a não aceitar pesquisadores dentro de suas aldeias, ou, pelo menos, vêem com bastante desconfiança a presença e o trabalho de tais pessoas. Há, inclusive, casos cada vez mais freqüentes de grupos cobrando pelo fornecimento de dados, apontando a possibilidade de que, não sentindo um retorno da pesquisa na melhoria de sua qualidade de vida, na garantia de seus direitos, passaram a enxergar as pesquisas como algo que só beneficia o pesquisador, ou uma ciência à qual eles não têm acesso, passando a cobrar financeiramente como forma de ganhar algo em troca dos dados fornecidos. Ouvimos relatos entre os kadiwéu (etnia com a qual temos trabalhado desde 1999), por exemplo, sobre pesquisadores que haviam publicado trabalhos sobre eles sem que eles soubessem ou autorizassem, o que fez com que proibissem a presença de tais pessoas em suas aldeias.

Todos esses aspectos nos remetem às questões éticas envolvidas nas pesquisas (e aqui, mais especificamente, nas pesquisas com grupos indígenas), mostrando a necessidade de uma reflexão acerca dos conhecimentos que têm sido produzidos nesse âmbito.

É certo que toda pesquisa, e todo paradigma adotado, traz consigo uma dimensão ética, um referencial do que se considera justo, bom, aceitável e o que se imagina quando se diz que se quer transformar algo, ou seja, todo psicólogo social, ao enfrentar uma problemática social que julga relevante, tem necessariamente, em mente, um referencial de como as situações devem ou deveriam ser quando mudadas e transformadas. Segundo Guareschi (2003) o problema é que esse referencial nunca é discutido, ele é apenas suposto, mas às vezes dentro de diferenças substanciais.

Assim, a questão, muitas vezes, não é que as pesquisas sejam éticas ou não éticas, mas, sim, que pressupõem um referencial ético que pode diferir substancialmente de uma para outra, remetendo a discussões polêmicas bastante complexas que ocorrem nas ciências humanas em geral, e, no caso do presente artigo, particularmente na ciência psicológica. Temos, na Psicologia, uma série de autores que vêm discutindo as questões éticas, não apenas no âmbito da pesquisa como também no da prática profissional. Temos, inclusive, um novo Código de Ética Profissional do Psicólogo, que passou por um processo de recentes modificações e mobilizou uma série de discussões envolvendo toda a categoria.

Na exposição de motivos do Código de Ética, que podem ser encontrados na página do Conselho Regional de Psicologia de São Paulo (www.crpsp.org.br), nos deparamos com um
Assim, a questão, muitas vezes, não é que as pesquisas sejam éticas ou não éticas, mas, sim, que pressupõem um referencial ético que pode diferir substancialmente de uma para outra, remetendo a discussões polêmicas bastante complexas que ocorrem nas ciências humanas em geral, e, no caso do presente artigo, particularmente na ciência psicológica. 
texto que apresenta uma visão do homem como ser fundamentalmente dinâmico e relacional. O discurso apresentado enfatiza que, sendo o homem sujeito e objeto de estudo da Psicologia, qualquer sistema ou código de ética só será real se sujeito, também ele, a essa transitoriedade que é própria do homem à procura de seu destino e significação. No texto, um código de ética deve expressar, de um lado, a dinamicidade e, de outro, um conjunto de ações ou comportamentos que seja representativo da realidade e da relatividade do dia-a-dia, com os quais o homem se põe diariamente em contato. Enfatiza também que um código será falho se fizer uma ética para o psicólogo, esquecendo-se da ética do homem, lembrando que a moralidade se concebe como atitude, qualidade e valores, e que a ética não pode proporcionar soluções préfabricadas sem que haja um trabalho interno de cada indivíduo propondo-se a agir eticamente. Por fim, esse Código afirma querer juntar as duas coisas: os grandes princípios e a prática do cotidiano, pretendendo ser fonte de uma reflexão ética não dissociada da prática profissional.

Para além dessa discussão envolvendo o Código de Ética, podemos citar autores que têm refletido as questões éticas no âmbito da Psicologia social, tais como Banchs (2000), Sawaia (1998), Crochík (1999) e Guareschi (2003), só para citar alguns dos estudiosos que têm falado dessa questão.

Na visão de Banchs (2000), a partir do momento em que nosso objeto de estudo ou de ação é o ser humano, nossa práxis está inserida em uma visão de mundo e de humanidade que são inevitavelmente políticas e que implicam necessariamente um sistema de valores. Para a autora, é fato que a Psicologia social, como toda ciência social, constitui uma prática ético-política, sendo esse fato um elemento central nas discussões teóricas e epistemológicas que desenham os contornos do espírito de nossa época.
Sawaia (1998) também vai enfatizar a unicidade que existe entre a discussão ética e a epistemológica, chamando a atenção para o fato de que a reflexão epistemológica explicita a dimensão ética do conhecimento, algo que foi cindido na história do pensamento científico, mas que se encontra estreitamente relacionado.

A autora vai iniciar suas reflexões levantando as seguintes questões: a Psicologia social é democrática? Qual o papel político do conhecimento que ela produz? E mais adiante, vai se perguntar: qual a ética que nossos pressupostos referendam? O conhecimento que tem sido produzido pela Psicologia continua gerando práticas democráticas ou excludentes, libertárias ou normatizadoras, fetichizadoras ou humanizadoras?

Essas questões não parecem desvinculadas das levantadas pelo construcionismo (para que e para quem determinado saber é produzido?) indicando aqui que a questão ética parte sempre de uma pergunta que questiona a serviço de que se encontra a produção do conhecimento científico e qual visão de ser humano está implícita (e explícita) no paradigma adotado.

Sawaia (1998) vai afirmar que um ponto de partida frutífero ao exercício da crítica epistemológica, que é, ao mesmo tempo, ética e ontológica, é a indagação sobre o sujeito presente em nossas pesquisas, teorias e práticas. Dessa forma, o debate que compete especificamente à Psicologia social é: o sujeito é coletivo ou individual, particular ou universal? Essa, na visão da autora, além de ser a questão central da Psicologia social, é a que carrega, de forma explícita, a questão ética.

Dessa forma, pensando no discurso de apresentação do Código de Ética assim como nas afirmações de Banchs (2000) e Sawaia (1998), vai-se tornando mais forte a idéia de que falar de ética, e, aqui neste caso, ética em pesquisa, é falar de um questionamento 
que não se limita a indagações tais como: a pesquisa envolve sujeitos vulneráveis? Pode causar dano às pessoas envolvidas? Como realizar o processo de consentimento informado? Ou seja, falar de ética em pesquisa é falar desses assuntos, mas questionar também, e fundamentalmente, a serviço do que e de quem será utilizado o conhecimento produzido, qual visão de ser humano está presente na investigação e quais as implicações e envolvimentos políticos da pesquisa.

Aqui se tornam interessantes as contribuições de Crochík (1999), que realiza um ensaio no qual procura examinar alguns conceitos subjacentes à relação entre ética, política e Psicologia, considerando-se a formação e atuação do psicólogo. Ele começa falando da separação que há entre a ética, a política e a Psicologia, e afirma que tal separação apresentaria um sentido emancipatório se o indivíduo, como objeto de interesse da teoria e da prática psicológicas, tivesse efetivamente a autonomia que se julga que ele tenha, algo que, no entanto, não ocorre. Isso faz com que a própria enunciação do tema corra o risco de se converter em ideologia, no sentido de camuflar a heteronomia que está subjacente aos atos políticos e éticos.

Para o autor, quando se considera a política associada à cidadania sem pensar no indivíduo, que é sua base, quando se compreende a ética sem a referência aos conflitos sociais, quando se pensa o indivíduo sem a mediação social que o constitui, tem-se uma visão deturpada da realidade, e, se a Psicologia, a política e a ética se relacionam na atualidade, o fazem de forma negativa, isto é, cada qual negando a outra. Para ele, no entanto:

“(...) a ética deve pautar-se pela construção coletiva de valores respaldados pela história, mas deve pedir pela adesão racional a eles; a política deve voltar-se para as condições materiais que possibilitem a realização daqueles valores, e a Psicologia deve tornar-se crítica à heteronomia, ou seja, voltar-se para as condições sociais que não permitem que o seu objeto - o indivíduo - seja o real sustentáculo da ética e da política, o que só seria possível quando sujeito e indivíduo coincidissem na História" (1999, pp. 49-50).

Após essa discussão, qual é, portanto, o referencial ético adotado em nossas pesquisas com populações indígenas? Qual a compreensão e reflexão ética que trazemos implícitos e explícitos em nosso fazer científico, em nossa produção de conhecimento que se dá no âmbito da Psicologia social?

De início, e já que, assim como Sawaia (1998), partimos da idéia de que epistemologia e ética não são áreas cindidas, é importante dizer que os nossos valores éticos não estão fundamentados nem no paradigma da lei natural e nem no paradigma da lei positiva. Adotamos, sim, a noção de ética como instância crítica, baseados na concepção de Dos Anjos (1996 apud Guareschi, 2003). Nessa concepção, a ética é uma instância crítica e propositiva sobre o dever ser das relações humanas em vista de uma plena realização dos seres humanos.

Segundo Guareschi (2003), a dimensão crítica da ética significa que ela não pode ser considerada algo pronto, acabado. Ao contrário, ela está sempre por se fazer, sendo uma busca infinita, incessante por crescimento e transformação. Ela precisa ser também propositiva, ou seja, não pode colocar apenas exigências e desafios, mas tais desafios precisam ser reelaborados, redimensionados.

Assim, segundo o autor, a crítica resgata a dimensão ética de toda ação humana, sem que se feche a questão sobre a presença de uma dimensão ética específica. Uma postura teórica que toma a ciência como uma prática que diz "como as coisas são" esconde, no fundo, uma postura conservadora, e "tanto uma como a outra possuem dimensões éticas, pois ser conservador é uma ação tão ética como lutar pela mudança" (2003, p.22). 
A outra dimensão fundamental dessa concepção é a da ética enquanto ética das relações, ou seja, a ética só pode se referir às relações, e ela mesma é sempre uma relação. Assim, ninguém pode dizer-se ético a partir de si mesmo, como postula o liberalismo. $\mathrm{O}$ pensamento liberal centraliza tudo no "eu". Perdemos, com isso, a dimensão relacional e mistificamos o verdadeiro sentido da ética (Guareschi, 2003).

Nas palavras de Sawaia (1998), o projeto libertário da modernidade contemporânea está assentado no sujeito autônomo, e sua economia está apoiada no princípio do desejo individual de ser feliz. Porém, essa ênfase no sujeito é constituída por uma ambigüidade: há uma valorização do sujeito, mas para instrumentalizá-lo e aprisioná-lo ao individualismo e narcisismo consumista, base de sustentação do projeto neoliberal. Tratase do sujeito individual, volátil, limitado em suas ações, fechado em si mesmo, embora com discurso participativo, em substituição à desintegração do sujeito coletivo dos espaços públicos.

A centralização no eu e a concepção de um sujeito individual fechado em si mesmo acaba por refletir-se em uma concepção de ética também individual, fechada e limitada a normas que, ao serem seguidas ou não, implicarão uma ação ética ou não ética. A centralização no eu, projetada no liberalismo, traz conseqüências importantes para refletirmos a ética, assunto sobre o qual não poderemos nos estender. O importante é chamar a atenção para a perda da sua dimensão relacional e sua limitação a regras que se fecham em uma "ética do psicólogo", ditada por normas e padrões a serem seguidos, esquecendo-se da própria ética do homem, como chama a atenção o texto de motivos do Código de Ética Profissional do Psicólogo, exposto anteriormente.

Dessa forma, há três pontos importantes de reflexão relacionados às pesquisas com grupos indígenas, à luz das concepções e discussões expostas acima:

Quando, enquanto psicólogas sociais, elegemos a problemática indígena como uma problemática social relevante, como um campo-tema ao qual a Psicologia social pode ser útil de alguma forma, almejamos mudanças, trazemos conosco um referencial de como o contexto poderia ser transformado, mas, almejamos uma transformação de acordo com que critérios valorativos e éticos?

Já expusemos a nossa compreensão de ética, mas qual o reflexo dessa compreensão para uma pesquisa com grupos indígenas? Assumir esse referencial ético significa assumir quais posições?

A nossa posição está relacionada à idéia de interintegração e a certeza de que as sociedades indígenas também se transformam. Ao contrário de um discurso que circula e é bastante comum na sociedade nacional, o índio não tem que ir para museu. Ele não tem que estar necessariamente vivendo de modo igual ao que vivia há quinhentos anos para que continue sendo índio. O problema é que a transformação da sociedade indígena se dá num processo de dominação por uma cultura alheia a sua, que se considera superior e se impõe sem respeito algum às diferenças étnicas e culturais.

Ao mesmo tempo, a idéia do isolamento total já não parece mais viável, e a questão passa a ser como transformar as relações entre populações indígenas, Estado e sociedade civil, ou seja, como passar de uma relação de domínio e imposição de uma cultura sobre a outra para uma relação efetivamente de troca, respeito e autonomia cultural, social e política. Dessa forma, tomamos a posição de que o ideal seria não a integração do índio (como se tem pretendido nos últimos quinhentos anos), mas a interintegração. O primeiro conceito significa a absorção de uma cultura pela outra, 
já o segundo quer dizer o diálogo, a complementação, respeitando as identidades, numa convivência pacífica e plural, sabendo que o Brasil, até mesmo por Constituição, é pluriétnico e pluricultural.

Assim, a transformação almejada pauta-se nessa idéia de diferentes culturas interintegrando-se uma à outra, trocando experiências, numa relação que implique simultaneamente igualdade de direitos e respeito às diferenças.

Além disso, como expusemos anteriormente, considerar um tema psicologicamente relevante não pode ser tomado como um processo simples. Há muitos que consideram que tornar algo psicologicamente relevante significa captá-lo, torná-lo parte integral da Psicologia, algo que só os psicólogos sabem ou que só os psicólogos têm habilidade de resolver. Aqui entramos, portanto, em uma escolha ética que precisa ser feita entre possessão ou contribuição, propriedade ou utilidade, entre ser um agrupamento de interesses privados ou ser parte da coletividade social (Spink, 2003). Neste ponto, a posição que tomamos em relação às nossas pesquisas é a de que a Psicologia pode trazer novas vozes e perspectivas ao debate acerca da questão indígena; a idéia não é se apossar de um campo ou disputar conhecimentos com outras ciências, mas acrescentar, ampliar, trocar, contribuir para uma questão que tem recebido pouca contribuição da ciência psicológica.

O outro ponto de reflexão diz respeito à dimensão crítica e propositiva da ética. O que essa dimensão implica para as pesquisas com populações indígenas?

Implica, por exemplo, uma posição de crítica em relação ao saber acumulado e a forma como esse saber tem sido produzido e utilizado ao longo da História. Referimo-nos aqui, novamente, à questão do abuso nas pesquisas com populações indígenas, pesquisas essas muitas vezes sem comprometimento algum com as populações estudadas e sem um retorno do saber produzido na melhoria da qualidade de vida dessas populações e na garantia de seus direitos. Assim, embora esse conhecimento acumulado (produzido principalmente pela Antropologia) tenha a sua importância, a crítica a um tipo de conhecimento descomprometido e fechado no mundo da ciência do "não índio" é cada vez maior. É também crescente a reivindicação por pesquisas cada vez mais comprometidas com a transformação nos discursos e nas ações políticas (cotidianas e estatais), assim como uma valorização maior dos conhecimentos tradicionais dos povos indígenas e o seu acesso à ciência produzida pelo não índio.

Essa concepção acarreta também uma posição em que a construção de soluções alternativas (proposições) aos problemas vividos pelas populações indígenas seja um dos pilares principais de toda e qualquer pesquisa, que deve, portanto, apoiar a autonomia dos índios, a valorização de seus saberes tradicionais e o respeito às formas escolhidas por eles para construir seus projetos de futuro, objetivando uma nova relação entre diferentes.

Por fim, considerando que toda a nossa postura implica uma dimensão ética e nossa ética vai diferenciar-se de acordo com nossa relação diante do "outro", é a esse aspecto (da ética enquanto ética das relações) que se refere o próximo ponto de reflexão.

- Dessa forma, o que podemos dizer da ética na relação entre índios e não índios no contexto de uma prática de pesquisa?

Antes de adentrarmos nessa discussão no âmbito da Psicologia social, refletindo sobre as experiências vividas em nossas pesquisas, queremos abordar brevemente o pensamento de um antropólogo que certamente traz contribuições ao tema.

Lévi-Strauss, não só por ter trabalhado e realizado investigações junto a grupos indígenas 
brasileiros mas também pelo reconhecimento que possui sua obra, traz importantes reflexões. Embora esse autor não tenha tratado da questão ética de forma explícita, podemos encontrar, em seus trabalhos, toda uma concepção e forma de atuação, de investigação e de relação com os grupos indígenas que contém, dentro de si, toda uma concepção de ética. Para além disso, ele traz também uma concepção de sujeito que explicita uma ética enquanto ética do ser humano, e não apenas do antropólogo, quando afirma a ilusão do "homem" ocidental de se considerar superior ao "homem" indígena.

Em sua obra O Pensamento Selvagem (1976), Lévi-Strauss vai afirmar que, quando cometemos o erro de crer que o indígena é exclusivamente governado por suas necessidades orgânicas ou econômicas, "não reparamos que ele nos dirige a mesma censura, e que, a seus olhos, seu próprio desejo de saber parece melhor equilibrado que o nosso" (p.21). Ele também abre mais uma ferida narcísica ao afirmar que o homem branco, ocidental, "civilizado", não detém a posição de superioridade ontológica como pretende; não pensa mais "adultamente", não alcançou o nível mais avançado de cultura em relação aos homens com outros costumes.

Esse importante estudioso vai também fazer a crítica a um tipo de investigação e a toda uma forma de circulação dos materiais obtidos em viagens etnográficas e que tomam uma aceitação pública, para ele, inexplicável. Na primeira parte dos Tristes Trópicos (1955), ele afirma, a esse respeito, que:

"A Amazônia, o Tibet, a África invadem as lojas sob a forma de livros de viagens, relatórios de expedições e álbuns de fotografias, em que a preocupação do efeito é demasiado predominante para que o leitor possa apreciar convenientemente o valor testemunhal que encerram (...). Ser explorador é agora uma profissão; profissão que não consiste (...) em encontrar, ao cabo de anos e anos de estudo, factos até então ocultos, mas sim em percorrer um número elevado de quilômetros, juntando diapositivos e filmes (...) graças aos quais se encherá uma sala (...) com uma multidão de ouvintes para os quais frases ocas e banalidades se transmutarão em revelações, pelo simples facto de o autor, em vez de localizá-las imediatamente, tê-las santificado com um percurso de 20.000 quilômetros" (1955, p.12).

Dessa forma, os trabalhos de Lévi-Strauss são uma referência importante para se pensar toda a questão ética envolvendo trabalhos junto a grupos indígenas, tanto na questão de como tratamos os materiais obtidos, como os fazemos circular, a serviço de que e de quem (preocupação já explicitada por ele, em uma época em que esses materiais pareciam ter valor pelo fato de virem de um lugar distante e considerado exótico, e não pelas reais contribuições científicas que continham) quanto em relação à questão da própria concepção de sujeito que possuímos, que condiciona também a forma como vamos nos relacionar. Se, como afirmou Lévi-Strauss, partimos de uma idéia de superioridade ocidental em relação ao indígena, a maneira como vamos nos relacionar é certamente diferente de quando nos posicionamos contrários a isso.

Há, portanto, em relação a esse tópico, inúmeros aspectos a serem discutidos. Inicialmente, podemos falar da questão da desconfiança que existe por parte dos índios em relação aos pesquisadores. Essa desconfiança se remete à questão ética justamente pelo caráter de relação, e por essa relação ser marcada por um sentimento particular e bastante intenso.

Pode-se dizer que os índios, em geral (lembrando aqui o fato de "índios" ser uma categoria construída ocidentalmente, que engloba uma diversidade de povos e culturas extremamente heterogêneos entre si, sendo 
usada apenas quando não nos referimos a alguma etnia específica), têm uma profunda desconfiança em relação a qualquer pessoa estranha, o que não é diferente com os pesquisadores. Por isso, há que se conquistar a sua confiança, o que não é algo nem fácil nem rápido. É algo que se constrói com o tempo (e com o tempo que é o tempo deles), com as vivências compartilhadas, experiências trocadas, enfim, com o desenrolar das relações. Mas a posição de alguém de quem se deve desconfiar, e de quem, de fato, se desconfia, é bastante desconfortável, e, às vezes, um tanto angustiante. É algo também que, de uma forma ou de outra, acaba relacionando-se com todo o processo da pesquisa, na medida em que as decisões do pesquisador (como alguém que não só escolhe, mas que é também escolhido) estão ligadas à forma como se estabeleceu a sua relação com os participantes (relação dinâmica e mutante). É interessante enfatizar, no entanto, que, com o tempo, fica claro que eles sabem "quem é quem", ou seja, a desconfiança serve como um termômetro da relação, que vai dizer-lhes quem entra e realiza o trabalho e quem não pode sequer permanecer na aldeia.

Dessa forma, a entrada em uma aldeia indígena não é simples. Depende de autorização dos órgãos federais considerados responsáveis_fundamentalmente, a Fundação Nacional do Índio (FUNAI) e a Fundação Nacional de Saúde (FUNASA) _ mas mais do que isso: das próprias lideranças indígenas. Portanto, a inserção na reserva indígena e a autorização para realizar as pesquisas estão essencialmente pautadas no consentimento das lideranças e dos órgãos responsáveis; o trabalho pode ser iniciado mesmo quando os papéis ainda estão tramitando (um processo burocrático bastante longo), desde que as lideranças tenham autorizado. Por outro lado, o pesquisador pode já ter os papéis em mão, mas, sem a autorização das lideranças, não poderá desenvolver pesquisa alguma.
A partir do momento em que a entrada do pesquisador na reserva ou aldeia é aceita, há ainda aspectos relacionados às formas como se construirá a sua relação com as pessoas da comunidade. Como já exposto, atualmente há diversos grupos indígenas que aceitam o trabalho do pesquisador desde que ele pague para realizar sua pesquisa, algo que não ocorreu conosco, mas que remete a questões éticas importantes e complexas, que não podem se resumir a uma discussão simplista em que pagar para realizar a pesquisa seja uma atitude não ética. Essa é, no entanto, uma discussão que merece ser tratada em sua complexidade, e não será aprofundada nesta exposição.

O que consideramos interessante discutir sobre esse tópico é o que diz respeito às trocas. É importante ressaltar que os índios, no geral, possuem uma relação explícita de troca, que é bastante interessante e não possui a mesma conotação que na nossa cultura, ou seja, mesmo quando os pesquisadores não são solicitados a pagar pela realização da pesquisa, ainda assim a troca pode aparecer como um elemento importante da relação.

Na relação com os índios kadiwéu, por exemplo, eles costumam pedir para que levemos determinadas coisas, que são às vezes de difícil acesso para eles, e conosco realizam trocas. As trocas são realizadas principalmente com as mulheres, e é difícil dizer em que se baseiam para saber o que deve ser trocado pelo que (a quantidade e a qualidade das coisas). De qualquer maneira, é algo que passamos a considerar natural, primeiro, porque não foi proposto ou imposto por nós, mas estabelecido na relação; segundo, porque as trocas têm uma conotação, na nossa cultura, muitas vezes pejorativa, com um sentido de "interesse" (de tirar proveito), algo que parece não possuir esse sentido para eles, caracterizando mais uma relação de cordialidade. Além disso, ao longo do tempo, passaram a ocorrer situações em que algo era presenteado e não, trocado, e essa ação é de grande valor, parecendo significar que a relação chegou a um nível maior de profundidade, afetividade e respeito. 
"...reconhecer o "fim jurídico" da tutela da União sobre os povos indígenas pela

Constituição de 1988 não significa o fim de formas de exercício de poder, de moralidades e de interação que se poderia qualificar de tutelares nem representa um novo projeto para o relacionamento entre povos indígenas, poderes públicose segmentos

dominantes da sociedade brasileira".

Barroso-Hoffmann
Outro ponto importante diz respeito à ação do pesquisador e ao fato de a relação com os índios não poder resumir-se à prática de pesquisa, ou seja, realizar uma pesquisa no âmbito da questão indígena é comprometerse com toda a causa indígena mais ampla, é comprometer-se com uma transformação da visão que se tem dos índios, do papel que eles exercem dentro do contexto político nacional, é rever e lutar pelo fim das relações baseadas no princípio da tutela, promover o diálogo intercultural, a interintegração entre sociedades indígenas e sociedade nacional envolvente, lutar pelo acesso pleno das etnias indígenas ao saber que tem sido produzido sobre elas pelo não índio ao longo de todos esses anos, lutar para que o não índio também perceba que, para se relacionar com os povos indígenas, necessita aprender com eles sobre eles, e, por fim, possibilitar também o acesso das etnias indígenas a todos os outros saberes que possam auxiliá-los em seu processo de autonomia política, cultural, econômica, na garantia de suas terras e no respeito aos seus direitos. Enfim, qualquer pesquisador que queira realizar trabalhos no âmbito da questão indígena deve estar, dentro de nossa concepção ética, articulado a essa rede mais ampla de discussão em relação aos direitos indígenas e às transformações necessárias para que esses direitos sejam ampliados e respeitados integralmente.

Nas palavras do antropólogo Geertz, olhar as dimensões simbólicas da ação social - arte, religião, ideologia, ciência, lei, moralidade, senso comum - não é afastar-se dos dilemas existenciais da vida; é, ao contrário, mergulhar nelas. A concepção essencial da Antropologia interpretativa "não é esconder as nossas questões mais profundas, mas colocar à nossa disposição outros carneiros em outros vales e assim incluí-las no registro de consultas sobre o que o homem falou" (1978, p.40).

Concordamos com Lima e Barroso-Hoffmann (2002) que é preciso afastar de vez a imagem do índio presente nos cronistas e viajantes, a imagem de um ser eternamente imerso na natureza, signo do exotismo dos trópicos americanos, parado em um tempo estagnado, vivendo em completa e total harmonia. É preciso também superar a idéia da sociedade indígena como um passado perdido da sociedade moderna, aquilo que a sociedade moderna jamais voltará a ser, assim como a idéia oposta, igualmente equivocada, da sociedade indígena como a infância da sociedade moderna, como aquilo que ela ainda não conseguiu alcançar.

Assumir essas idéias e valores é assumir uma posição ética, uma posição relacionada a uma determinada concepção de ética, exposta por nós. Posicionar-se dentro desses valores ao realizar pesquisas com grupos indígenas é fundamental para que não se continue repetindo os mesmos abusos e atrocidades que têm sido cometidos ao longo da História com relação a essa população.

Como afirmam Lima e Barroso-Hoffmann (2002), reconhecer o "fim jurídico" da tutela da União sobre os povos indígenas pela Constituição de 1988 não significa o fim de formas de exercício de poder, de moralidades e de interação que se poderia qualificar de tutelares nem representa um novo projeto para o relacionamento entre povos indígenas, poderes públicos e segmentos dominantes da sociedade brasileira. A nosso ver, cabe também aos pesquisadores a busca por alternativas e por novas formas de relacionamento com essas populações, para que não se perpetuem, sob outras vestes e máscaras, as mesmas formas de interação baseadas no princípio da tutela. Assim, a partir dessas reflexões, podemos chegar a algumas possibilidades de respostas àquelas indagações iniciais.

Em relação à pergunta (para quem e para que determinado saber é produzido) a reflexão nos aponta a possibilidade de respostas por parte dos próprios grupos indígenas, ou seja, para 
que e para quem determinado saber é produzido é uma pergunta cuja resposta eles é que podem dar, as pessoas da comunidade com a qual se vai trabalhar, num processo de construção conjunta da pesquisa. Dentro da concepção ética que trazemos, essa não é uma pergunta para ser respondida de forma individual, mas sim, em conjunto, coletivamente. Eles é que têm que apontar a importância ou não da pesquisa, a relevância ou não desta para os problemas vividos por eles. Não é preciso buscar respostas em discursos caducos; é possível recriar uma perspectiva na qual os participantes dizem o que é uma ação realmente relevante para eles, em direção a uma interintegração de saberes, em que haja valorização e contribuição dos conhecimentos tradicionais dos povos indígenas assim como dos conhecimentos e tecnologias produzidos pelos não índios, ambos interintegrados em busca de soluções alternativas para os problemas. Acreditamos que, nesse processo, o psicólogo social pode ser de grande utilidade, trazendo novas perspectivas ao debate e contribuindo para a procura de soluções alternativas para os problemas indígenas, junto a eles.

Finalizando, o que consideramos essencial, e que também reivindicamos, com o construcionismo, "é a necessidade de remeter a verdade à esfera da ética: pontuar sua importância não como verdade em si, mas como relativa a nós mesmos" (Spink \& Frezza, 1999, p.30).

É o que procuramos fazer neste artigo dedicado à discussão da ética na pesquisa ou o que consideramos uma pesquisa ética junto às populações indígenas do Brasil.

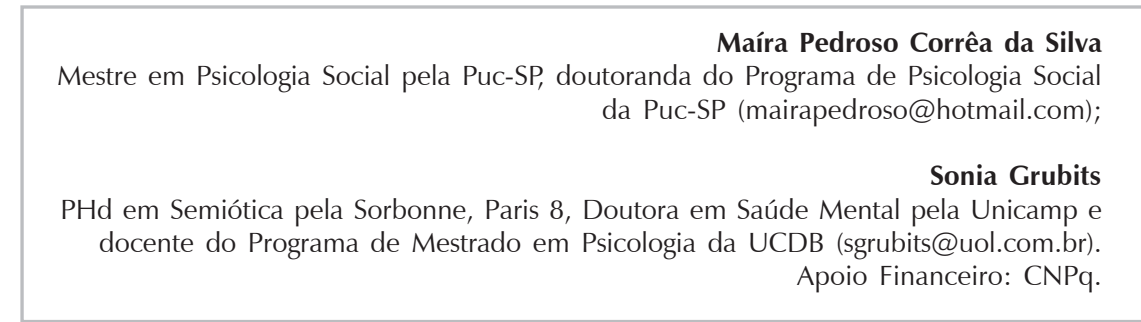

Recebido 03/01/05 Reformulado 04/08/05 Aprovado 03/03/06

BANCHS, M. A. La Psicologia Social como Practica Político Ética: Reflexiones en torno a la Arista Subjetiva de las Representaciones Sociales. In Psicologia \& Sociedade, 12 (1/2), jan./dez. 2000, pp. $32-53$

CROCHÍK, J.L. Notas sobre a Formação Ética e Política do Psicólogo. In Psicologia \& Sociedade, 11 (1), jan./jun. 1999, pp. 27-51.

GEERTZ, C. A Interpretação das Culturas. Rio de Janeiro: Zahar, 1978.

GUARESCHI, P. A. Ética e Paradigmas. In K. S. Ploner, L. F. Michels, L. M. Schlindwein, P. A. Guareschi (orgs.). Ética e Paradigmas na Psicologia Social. Porto Alegre: ABRAPSOSUL, 2003.

LÉVI-STRAUSS, C. Tristes Trópicos. Trad.:Jorge Constante Pereira. Lisboa: Portugália Editora, 1955.

LÉVI-STRAUSS, C. O Pensamento Selvagem. Trad: Maria Celeste da Costa Souza e Almir de O. Aguiar. São Paulo: Ed. Nacional, 1976.
LIMA e BARROSO-HOFFMANN. Questões para uma Política Indigenista: Etnodesenvolvimento e Políticas Públicas. Uma Apresentação. In A. C. de Souza Lima e M. Barroso-Hoffmann (orgs.). Etnodesenvolvimento e Políticas Públicas: Bases para uma Nova Política Indigenista. Rio de Janeiro: Contra Capa Livraria/ LACED, 2002.

SAWAIA, B.B. A Crítica Ético-epistemológica da Psicologia Social pela Questão do Sujeito. In Psicologia \& Sociedade, 10(2),jul./dez.1998, pp. 117-136.

SPINK, M.J.P. \& FREZZA, R.M. Práticas Discursivas e Produção de Sentidos: a Perspectiva da Psicologia Social. In M.J.Spink (org.). Práticas Discursivas e Produção de Sentidos no Cotidiano: Aproximações Teóricas e Metodológicas. São Paulo: Cortez, 1999.

SPINK, P. Pesquisa de Campo em Psicologia Social: uma Perspectiva Pós-construcionista. Texto organizado por Spink e membros do Núcleo de Organização e Ação Social. Programa de Pósgraduação em Psicologia Social da Puc-SP, 2003.
Referências 